\title{
Molecular heterogeneity in the novel fusion gene APIP-FGFR2: Diversity of genomic breakpoints in gastric cancer with high-level amplifications at 11 p13 and $10 q 26$
}

\author{
TAKASHI OKUDA ${ }^{1,2}$, TOMOHIKO TAKI ${ }^{3}$, KAZUHIRO NISHIDA ${ }^{2}$, YOSHIAKI CHINEN ${ }^{2}$, \\ HISAO NAGOSHI ${ }^{2}$, CHOUHEI SAKAKURA $^{4}$ and MASAFUMI TANIWAKI ${ }^{2}$ \\ ${ }^{1}$ Department of Gastroenterology and Hepatology; ${ }^{2}$ Department of Hematology and Oncology; \\ ${ }^{3}$ Department of Molecular Diagnostics and Therapeutics; ${ }^{4}$ Department of Digestive Surgery, \\ Kyoto Prefectural University of Medicine Graduate School of Medical Science, Kyoto 602-8566, Japan
}

Received May 22, 2015; Accepted September 28, 2016

DOI: $10.3892 / \mathrm{ol} .2016 .5386$

\begin{abstract}
Several novel fusion transcripts were identified by next-generation sequencing in gastric cancer; however, the breakpoint junctions have yet to be characterized. The present study characterized a plethora of APIP-FGFR 2 genomic breakpoints in the SNU-16 gastric cancer cell line, which harbored homogeneously staining regions (hsrs) and double minute chromosomes. Oligonucleotide microarrays revealed high-level amplifications at chromosomes 8q24.1 (0.8 Mb region), $10 \mathrm{q} 26$ $(1.1 \mathrm{Mb})$ and $11 \mathrm{p} 13(1.1 \mathrm{Mb})$. These amplicons contained MYC and $P V T 1$ at chromosome 8q24.1, BRWD2, FGFR2 and ATE1 at chromosome 10q26, and 24 genes, including APIP, CD44, $R A G 1$ and $R A G 2$, at chromosome 11p13. Based on these findings, reverse transcription-polymerase chain reaction (PCR) was performed using various candidate gene primers to detect possible fusion transcripts, and several products using primer sets for the APIP and FGFR2 genes were detected. Eventually, three in-frame and two out-of-frame fusion transcripts were detected. Notably, PCR analysis of the entire genomic DNA detected three distinct genomic junctions. The breakpoints were within intron 5 of $A P I P$, which contained three distinct breakpoints, and introns 5, 7 and 9 of $F G F R 2$. Fluorescence in situ hybridization showed several fusion signals within
\end{abstract}

Correspondence to: Dr Tomohiko Taki, Department of Molecular Diagnostics and Therapeutics, Kyoto Prefectural University of Medicine Graduate School of Medical Science, 465 Kajii-cho, Kawaramachi-Hirokoji, Kamigyo-ku, Kyoto 602-8566, Japan E-mail: taki-t@umin.net

Professor Masafumi Taniwaki, Department of Hematology and Oncology, Kyoto Prefectural University of Medicine Graduate School of Medical Science, 465 Kajii-cho, Kawaramachi-Hirokoji, Kamigyo-ku, Kyoto 602-8566, Japan

E-mail: taniwaki@koto.kpu-m.ac.jp

Key words: gastric cancer, homogenously staining region, genomic amplification, APIP, FGFR2 hsrs using two short probes ( $10-\mathrm{kb}$ segments of a bacterial artificial chromosome clone) containing exons 2-5 of APIP or exons 11-13 of FGFR2. Although, for any given fusion, a multiplicity of transcripts is thought to be created by alternative splicing of one rearranged allele, the results of the present study suggested that genomic fusions of APIP and FGFR2 are generated in hsrs with a diversity of breakpoints that are then faithfully transcribed.

\section{Introduction}

Gastric cancer is the second most common cause of cancer-associated mortality worldwide $(1,2)$. Multiple genomic alterations accumulate during the development and progression of gastric cancer. Mutations of tumor suppressor genes and oncogenes, including APC (3), KRAS (4), TP53 (5), RUNX3 (6), E-cadherin (7) and $\beta$-catenin (8), have been reported, along with amplifications of MYC (9), FGFR2/KSAM (10), MET (11) and $H E R 2 / E R B B 2$ (12). In addition, previous studies have identified a large number of fusion transcripts, including AGTRAP-BRAF, FPPP1RB-STARD3, DUS4L-BCAP29 and $P V T 1$ fusions with six different partners, using next-generation transcriptome sequencing (13-15).

Characterization of chromosomal translocations and inversions may help to identify genes implicated in the development of epithelial tumors and hematological malignancies. CD44-SLC1A2 was recently identified in a paracentric chromosomal inversion at chromosome 11p13-15 in gastric cancer (16); however, karyotypic analysis of gastric cancer, including spectral karyotyping (SKY), has been precluded by the complicated and cryptic nature of rearrangements (17). Conversely, homogeneously staining regions (hsrs) and double minute chromosomes (dmins), which are cytogenetic manifestations of high-level DNA amplifications, are easily characterized using high-resolution oligonucleotide microarrays. Combined with next-generation transcriptome sequencing, oligonucleotide microarrays identified several fusion transcripts associated with genomic amplification in various solid tumors, including lung cancer and medulloblastoma, that harbored hsrs and dmins (18-20). The identification 
of fusion transcripts may help researchers to develop novel therapeutic strategies and elucidate the molecular mechanisms underlying carcinogenesis. Furthermore, characterization of genomic fusions and breakpoint junctions may help to elucidate the mechanisms of fusions associated with DNA amplification.

The present study aimed to identify fusion genes associated with genomic amplification in gastric cancer. A comprehensive molecular analysis of high-level DNA amplifications in a gastric cancer cell line harboring hsrs and dmins, SNU-16, was performed. Several APIP-FGFR2 fusion transcripts were identified with diverse genomic breakpoints.

\section{Materials and methods}

Gastric cancer cell lines. Nine gastric cancer cell lines, including SNU-16, MKN-1, MKN-45, SNU-5, KATO-III, HGC-27, NUGC-4, SH-10 and H-111, were analyzed. SNU-16 and SNU-5 cell lines were obtained from the Korean Research Institute of Bioscience and Biotechnology (Taejon, South Korea). MKN-1, MKN-45, KATO-III, HGC-27, NUGC-4, SH-10 and H-111 cell lines were obtained from the RIKEN BioResource Center (Tsukuba, Japan). The culture conditions were described previously (17).

Chromosome preparation and DNA/RNA extraction. Metaphase spreads of tumor cells were prepared from a short-term culture of SNU-16 cells, which were derived from a poorly-differentiated adenocarcinoma. Genomic DNA was extracted using the Wizard Genomic DNA Purification kit (Promega Corporation, Madison, WI, USA). Total RNA was extracted using the Isogen-LS kit (Nippon Gene, Co., Ltd., Tokyo, Japan). Total RNA ( $4 \mu \mathrm{g}$ ) was reverse transcribed into cDNA in a total volume of $33 \mu \mathrm{l}$ with random hexamers using the Ready-To-Go You-Prime First-Strand Beads (GE Healthcare Life Sciences, Chalfont, UK).

Genome copy number analysis. Genome copy number analysis was performed using the Genome-Wide Human single nucleotide polymorphism (SNP) Array 6.0 (Afffymetrix Inc., Santa Clara, CA), according to the manufacturer's protocol. The copy numbers and chromosomal regions with gains or losses were individually evaluated using the Copy Number Analyzer for Affymetrix GeneChip (CNAG) 3.3.0.0 program (21). The genomic breakpoint was defined as lying within the boundaries marked by copy number changes. This region was then mapped on the National Center for Biotechnology Information MapViewer platform (http://www.ncbi.nlm.nih.gov/mapview/) and the precise breakpoint region was determined on the physical map.

Reverse transcription ( $R T)$-polymerase chain reaction (PCR), genomic PCR and sequencing analyses. RT-PCR and genomic PCR analyses were performed using the AmpliTaq Gold 360 Master Mix (Applied Biosystems; Thermo Fisher Scientific, Inc., Waltham, MA, USA), as described previously (22). Briefly, after 35 rounds of PCR (30 sec at $94^{\circ} \mathrm{C}, 30 \mathrm{sec}$ at $55^{\circ} \mathrm{C}$ and $1 \mathrm{~min}$ at $72^{\circ} \mathrm{C}$ ), $5 \mu \mathrm{l}$ of PCR product was separated by $3 \%$ agarose gel electrophoresis. The PCR primers used for detecting the APIP-FGFR2 fusions are shown in Table I.
Table I. Primers used for PCR.

\section{A, RT-PCR}

\begin{tabular}{lc}
\hline Primer & Sequence \\
\hline $\begin{array}{l}\text { Forward } \\
\text { APIP-1-2S (exon 1) } \\
\text { Reverse } \\
\text { FGFR2-11A (exon 11) }\end{array}$ & TCGGGAGGGAGACTGTTGTT \\
\hline B, Genomic PCR & \\
\hline Primer & Sequence \\
\hline
\end{tabular}

Forward

MMRP19-4S-2

CTCTTTCCAGGACGGGAGTT (APIP exon 5)

Reverse

FGFR2-1123P6A

ACGTGTGATTGATGGACCCG

(exon 6)

FGFR2-8bA

CACGTATATTCCCCAGCGTC

(exon 8)

FGFR2-1123P10A

(exon 10)

RT, reverse transcription; PCR, polymerase chain reaction.

The nucleotide sequences of the PCR products and, if necessary, those of subcloned PCR products were analyzed as described previously (22). RT-PCR for detecting $P V T 1-P D H X$, PVT1-ATE1, CLN6-CALML4, APIP-PVT1, CD44-FGFR2, PVT1-PPAPDC1A and CD44-SLC1A was performed as described previously $(14,16)$.

Fluorescence in situ hybridization (FISH) analysis. Double-color FISH (DC-FISH) analysis was performed as described previously $(17,23)$. Briefly, the bacterial artificial chromosome (BAC) clones RP11-412L22, RP11-62L18 and CTD-3056O22 (Advanced GenoTechs Co., Tsukuba, Japan) were used as probes to assess APIP, FGFR2 and MYC rearrangements in tumor cells, respectively. To detect the chromosomal fusion of APIP and FGFR2, DC-FISH analysis using two different probes, L4 and L1, which were prepared from $\sim 10-\mathrm{kb}$ long-distance PCR products obtained from RP11-412L22 and RP11-62L18 templates, respectively, was performed. For the long-distance PCR, each reaction mixture $(50 \mu \mathrm{l})$ contained $1 \mathrm{ng}$ BAC DNA, $10 \mathrm{pmol}$ of each primer, $8 \mu \mathrm{l}$ of dNTP mixture (2.5 mM each), $5 \mu \mathrm{l}$ LA PCR Buffer II and 2.5 U of Takara LA Taq HS (Takara Bio, Inc., Otsu, Japan). Reaction conditions were as follows: denaturation at $94^{\circ} \mathrm{C}$ for $1 \mathrm{~min}$, followed by 30 cycles of denaturation at $98^{\circ} \mathrm{C}$ for $20 \mathrm{sec}$, annealing and extension at $68^{\circ} \mathrm{C}$ for $10 \mathrm{~min}$ with 15 -sec increments per cycle, and a final extension at $72^{\circ} \mathrm{C}$ for 10 min. L4 contained exons 2-5 of APIP (nucleotides 118, 330-128, 595 in RP11-412L22), and L1 contained exons 11-13 of FGFR2 (nucleotides 27, 769-38, 427 in RP11-62L18). 

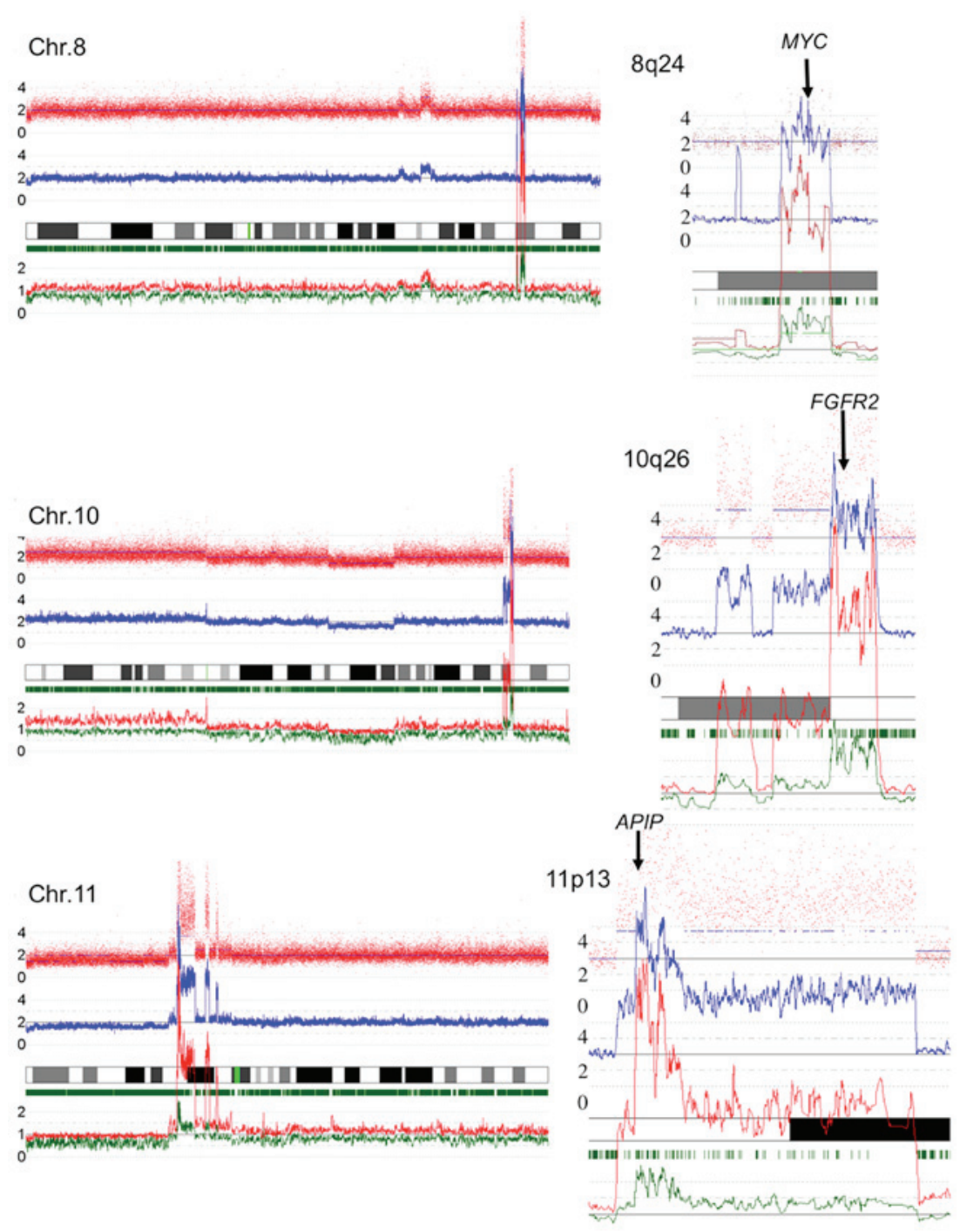

Figure 1. Amplification of 8q24.1, 10q26 and 11p13 in SNU-16 cells, as demonstrated using genome copy number analysis. Genome copy number analysis of the SNU-16 cell line revealed high-level amplifications at Chr. 8q24.1 (0.8 Mb region), 10q26 (1.1 Mb) and 11p13 (1.1 Mb). These amplified regions contained $M Y C$ and $P V T 1$ at 8q24.1, BRWD2, FGFR2 and ATE1 at 10q26, and 24 genes, including APIP, CD44, RAG1 and RAG2, at 11p13. Chr., chromosome.

RT-quantitative (q)PCR. The mRNA expression levels of $F G F R 2$ in the gastric cancer cell lines were determined using the TaqMan Universal Master Mix (Applied Biosystems; Thermo Fisher Scientific, Inc.) with specific primer probe sets from the ABI Assays-on-Demand ${ }^{\text {TM }}$ (Applied Biosystems; Thermo Fisher Scientific, Inc.) and on the ABI Prism 7300 system (Applied Biosystems; Thermo Fisher Scientific, Inc.), according to the manufacturer's protocol. After an incubation at $95^{\circ} \mathrm{C}$ for $10 \mathrm{~min}$, the cDNA was amplified for 40 cycles of denaturation at $95^{\circ} \mathrm{C}$ for $15 \mathrm{sec}$ and combined annealing/ extension at $60^{\circ} \mathrm{C}$ for $1 \mathrm{~min}$. Each sample was analyzed in duplicate. The primer set used was the Assays-on-Demand ${ }^{\mathrm{TM}}$ FGFR2 15-16 (Hs01552919_m1). Data were calculated using the relative standard curve method, and the mRNA levels were normalized to that of $\beta$-actin.

\section{Results}

Identification of APIP-FGFR2 fusion transcripts. In our previous study, SKY and FISH identified hsrs and dmins in the SNU-16 cell line (17). Therefore, in the present study, genome copy number analysis using SNP arrays was performed to identify precise genomic changes in the amplicons. High-level amplifications at chromosomes 8q24.1 $(0.8 \mathrm{Mb}$ region), 10q26 $(1.1 \mathrm{Mb})$ and $11 \mathrm{p} 13(1.1 \mathrm{Mb})$ were observed (Fig. 1). These amplified regions contained $M Y C$ and $P V T 1$ at chromosome 8q24.1, BRWD2, FGFR2 and ATE1 at chromosome 10q26 and 24 genes, including APIP, $C D 44$, $R A G 1$ and $R A G 2$, at chromosome 11p13. Based on these findings, RT-PCR using various candidate gene primer sets was performed to detect fusion transcripts. Using combination sets of primers for APIP and FGFR2, several PCR products, markedly different in size, were successfully amplified (Fig. 2A). Sequence analysis of these PCR products detected three in-frame and two out-of-frame fusion transcripts (Fig. 2B). For one of the in-frame fusion transcripts, the fusion point was within exon 6 of APIP and exon 10 of FGFR2; however, the corresponding band to this transcript was not found on the gel of separated RT-PCR products (Fig. 2A). Putative predominant APIP-FGFR2 fusion proteins commonly retained the N-terminal 18 amino acids of APIP and the catalytic domain of FGFR2 (Fig. 2C). 


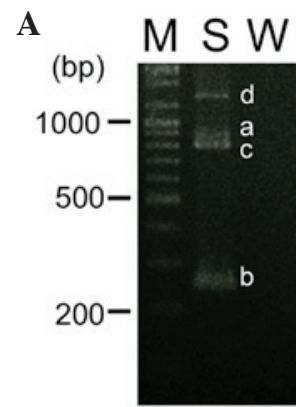

C

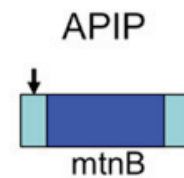

B In-frame fusion

$\begin{array}{lll} & \text { APIP } & \text { FGFR2 } \\ \text { a exon } 1 \downarrow & \text { exon } 6\end{array}$

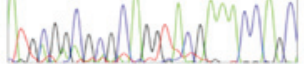

b exon $1 \downarrow$ exon 10
Out-of-frame fusion

APIP, FGFR2

C exon $1 \downarrow$ exon 7

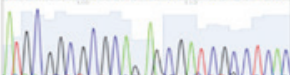

d exon $5 \downarrow$ exon 6

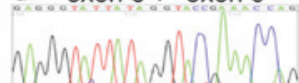

e exon $6 \downarrow$ exon $10 \mid$ exon 11
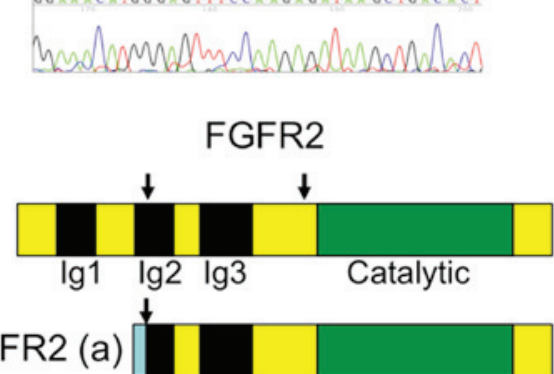

APIP-FGFR2 (b)

Figure 2. Cloning of the APIP-FGFR2 fusion gene. (A) Detection of APIP-FGFR2 chimeric transcripts using reverse transcription-polymerase chain reaction. Primers were APIP-1-2S and FGFR2-2A. (B) Sequencing of three in-frame (a, b and e) and two out-of-frame (c and d) APIP-FGFR2 fusion transcripts. Vertical arrows indicate the fusion points. Transcripts a, b, c and d correspond to those in (A), while transcript e was not found. (C) Schematic representation of putative APIP, FGFR2 and APIP-FGFR2 proteins. Vertical arrows indicate breakpoints or fusion points. M, size marker; S, SNU-16 cells; W, water; mtnB, methylthioribulose-1-phosphate dehydratase domain; Ig1-3, immunoglobulin-like domain 1-3.
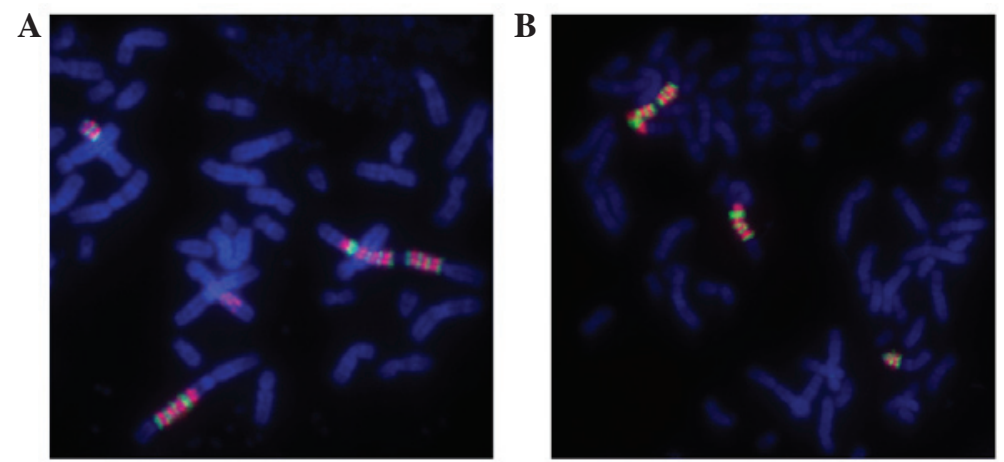

Figure 3. Dual color-fluorescence in situ hybridization analysis using BAC clones targeting APIP, FGFR2 and MYC. Tandemly repeated amplifications of (A) APIP (green) and FGFR2 (red) and (B) MYC (green) and FGFR2 (red) were observed in homogeneously staining regions. BAC clones targeting APIP (RP11-412L22), FGFR2 (RP11-62L18) and MYC (CTD-3056O22) were used as probes. BAC, bacterial artificial chromosome.
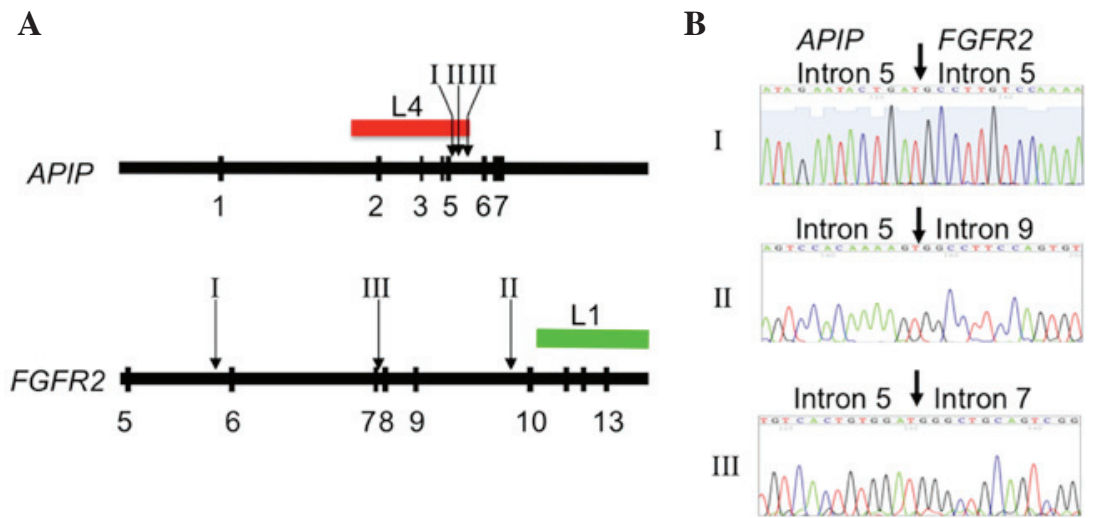

Figure 4. (A) Schematic illustration of genomic breakpoint regions in APIP and FGFR2 in the SNU-16 cell line. Vertical arrows indicate the fusion points of three clones (I, II and III) detected in the same SNU-16 cell line. L1 (green) and L4 (red) are probes used for the fluorescence in situ hybridization analysis. (B) Sequencing of three APIP-FGFR2 genomic junctions. Vertical arrows indicate the fusion points. 
A

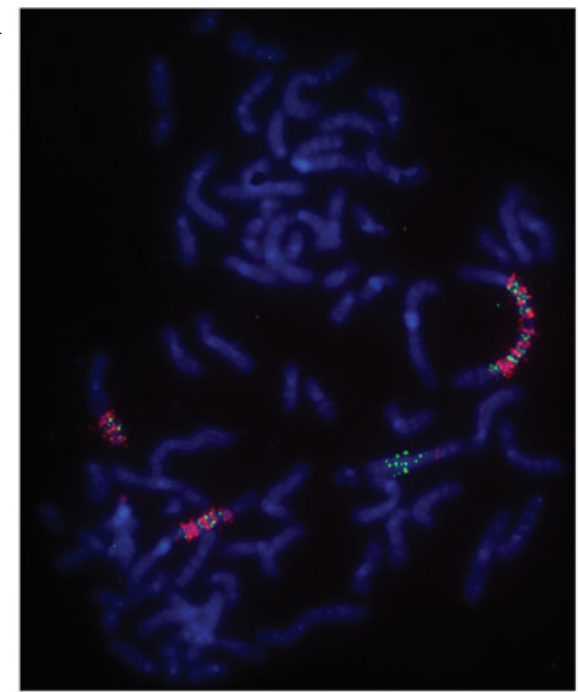

B

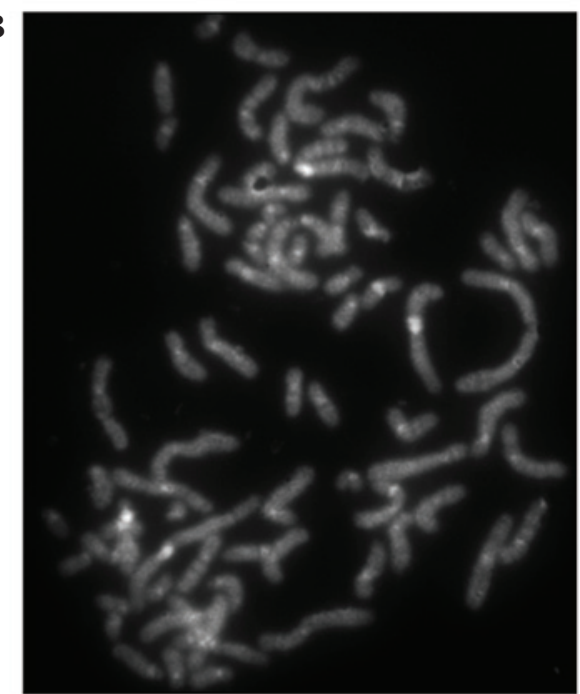

C

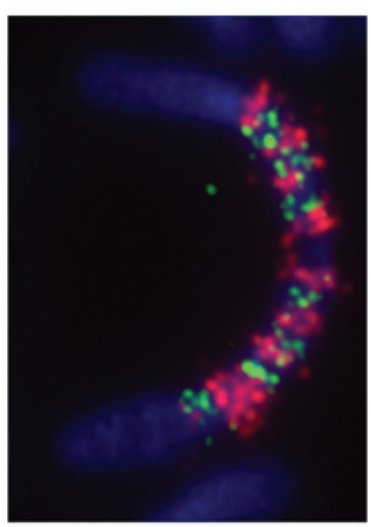

D

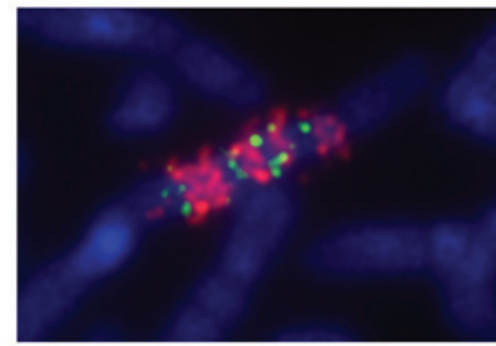

E

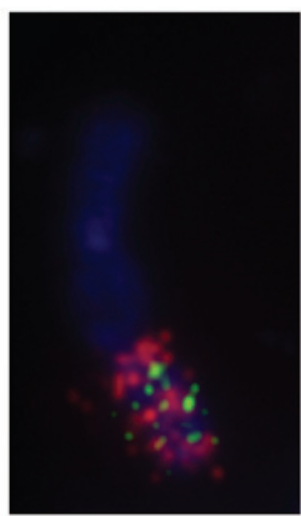

Figure 5. DC-FISH analysis using a probe set consisting of two long-distance polymerase chain reaction products ( 10 kb in size). (A) DC-FISH analysis was performed using L4 (red), containing exons 2-5 of APIP, and L1 (green), containing exon 10 of FGFR2 (magnification, x1,000). (B) DAPI image corresponding to the metaphase of (A), which was captured in conjunction with spectral classifications as inverted Q-bands by fluorescence using Hoechst 33258 for the identification of chromosomal breakpoints. (C-E) Enlarged views of tandemly repeated amplifications of $A P I P$ and FGFR2 in three homogeneously staining regions within (C). DC-FISH, dual color-fluorescence in situ hybridization.

Detection of tandemly repeated amplification of APIP, FGFR2 and MYC in hsrs. To confirm the fusion of APIP and FGFR2, DC-FISH analysis was performed using two BAC clones, RP11-412L22 (161 kb), encompassing the entire APIP gene, and RP11-62L18 (174 kb), encompassing the entire FGFR2 gene. No fusion was detected, but alternative and intense signals of APIP and FGFR2 were detected in three hsrs in SNU-16 cells, indicating that both genes were amplified and tandemly repeated in hsrs (Fig. 3A). Subsequently, DC-FISH was repeated using probes for FGFR2 and $M Y C$, which demonstrated an identical alternative pattern of amplified signals in three hsrs (Fig. 3B). The MYC FISH signals were observed in regions assigned to $A P I P$. These results suggested that the APIP, FGFR2 and MYC loci were amplified and tandemly repeated in the same hsrs.

Identification of genomic fusions between APIP and FGFR2. As no fusion of APIP and FGFR2 was detected by FISH using BAC clones, the genomic fusion points of APIP and FGFR2 were cloned. Long-distance PCR detected three genomic junctions. All three breakpoints detected in APIP were within intron 5; however, those in FGFR2 were within three different introns, including introns 5, 7 and 9 (Fig. 4A and B).
Further DC-FISH analysis was performed using a probe set consisting of two long-distance PCR products ( $10 \mathrm{~kb}$ in size) (Fig. 4A). These smaller probes detected not only tandemly repeated amplifications of $A P I P$ and $F G F R 2$, but also several fusion signals (yellow signals) in hsrs, although these fusion signals could not be fixed definitely because of yellow signals among the too many number of APIP and FGFR2 signals in the hsrs (Fig. 5A-E). These results suggest that several $A P I P-F G F R 2$ fusion genes may be generated with different fusion breakpoints within the same hsrs.

Expression of FGFR2. The expression level of FGFR2 in SNU-16 cells was analyzed and compared with that of several other gastric cancer cell lines using RT-qPCR (Fig. 6). FGFR2 was highly expressed in SNU-16, KATO-III and HGC-27 cells. Furthermore, the FGFR2 region was highly amplified in KATO-III cells, but not in HGC-27 cells (data not shown).

\section{Discussion}

The present study identified the APIP-FGFR 2 fusion gene in the SNU-16 cell line, which shows a high level of genomic amplification at chromosomes 8q24.1, 10q26 and 11p13. The APIP and 


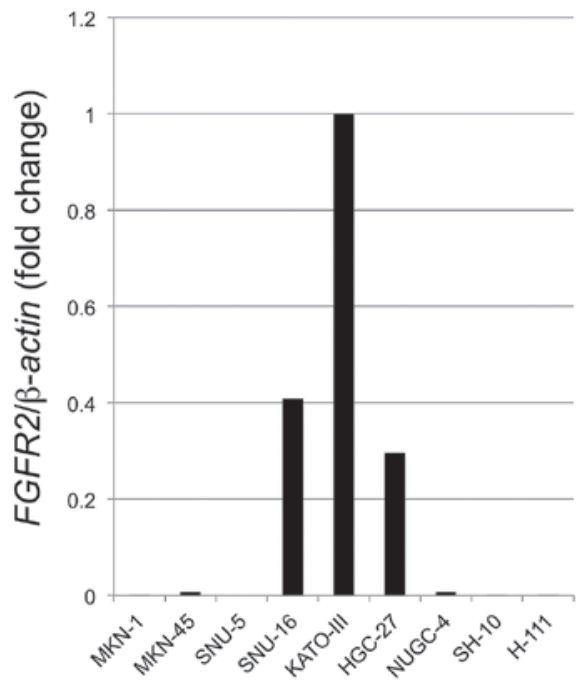

Figure 6. Relative mRNA expression levels of FGFR2 in gastric cancer cell lines, as compared with that of the KATO-III cell line, which was set to an expression level of 1 .

FGFR2 genes were in amplicons from chromosomes $11 \mathrm{p} 13$ and 10q26, respectively. The SNU-16 cell line has also been reported to have many fusions, including CD44-SLClA2 (16), PVT1-PDHX, CLN6-CALML4, APIP-PVT1, PVT1-ATE1, $P V T 1-P P A P D C 1 A$ and CD44-FGFR2 (14). Of these, $P P A P D C 1 A, F G F R 2$ and ATE1 are within $\sim 1.5 \mathrm{Mb}$ at $10 \mathrm{q} 26$, and the CD44, SLC1A2, PDHX and APIP genes are within $\sim 500 \mathrm{~kb}$ at $11 \mathrm{p} 13$. Notably, in the present study, all these genes, with the exception of PPAPDC1A, were within the same amplicons in SNU-16 cells. Kim et al (14) performed next-generation transcriptome sequencing analysis and detected six types of fusion transcripts in the SNU-16 cell line; however, APIP-FGFR2 and CD44-SLCIA2 were not observed. Of these fusion transcripts, the present study confirmed the presence of PVT1-PDHX, PVT1-ATE1, CLN6-CALML4, APIP-PVT1 and CD44-FGFR2, but not PVT1-PPAPDC1A or CD44-SLC1A, in the SNU-16 cell line using RT-PCR. One possible explanation for this discrepancy is that the expression levels of APIP-FGFR 2 and CD44-SLCIA2 were too low to be detected by next-generation transcriptome sequencing. Of the six fusion genes identified by next-generation transcriptome sequencing, only 2-10 junction reads of a total of 72,641,230 reads were sequenced for APIP-PVT1, PVT1-ATE1, PVT1-PPAPDC1A and CD44-FGFR2 (14). Therefore, abundance may be a limiting factor in the detection of fusion transcripts using next-generation transcriptome sequencing.

It is uncertain whether the fusion transcripts detected in gastric cancer cell lines are recurrent or not in clinical samples. In a previous study, CD44-SLC1A2 was detected in only 3 of 149 clinical samples (16), while other fusion transcripts have never been analyzed in clinical samples (14). Unfortunately, the present study did not have enough clinical samples to analyze these fusion transcripts and, thus, SNP array analysis was performed using array data deposited in the Gene Expression Omnibus (GEO) database. CEL files of 243 clinical samples, including 193 from Singapore (GEO accession: GSE31168) (4) and 50 from Russia or Vietnam (GEO accession: GSE29996) (24), were analyzed using Genotyping
Console (Affymetrix, Inc.) and CNAG3.3.0.0 or CNAG3.5.1. A total of 15 cases (6\%) were found to have copy number gains at the 10q26 region involving FGFR2, including 12 cases from Singapore (4) and 3 cases from Russia/Vietnam (24). Of these, 4 cases (011LGE, 75554796T, 980417T and 990172T) had gains of the $11 \mathrm{p} 13$ region involving APIP. These results suggested that $F G F R 2$ rearrangement is a recurrent abnormality in gastric cancer, and that $A P I P$ rearrangement is an abnormality related to $F G F R 2$ rearrangement.

Five APIP-FGFR 2 fusion transcripts were identified in the present study. These transcripts appeared to originate from variants of $A P I P$ and $F G F R 2$ genomic fusions with distinct breakpoint junctions, although some splicing variants may have been included. High-resolution FISH mapping using short probes ( 10-kb long-distance PCR products, L1 and L4) supported this notion by demonstrating possible fusion between APIP and FGFR2 in hsrs, while FISH using BAC probes (161 and $174 \mathrm{~kb})$ showed only an alternative pattern of amplified signals. A diversity of genomic breakpoints in fusion genes among cases is commonly observed for various fusions caused by chromosome abnormalities; however, the diversity of genomic breakpoints in a fusion gene identified in a single case showing high-level amplifications has not previously been well analyzed. Functional analysis of the molecular diversity exhibited by these fusion transcripts is required to reveal their biological significance and tumorigenic potential in gastric cancer.

In a previous study, next-generation transcriptome sequencing revealed that $A P I P$ and FGFR2 were fused to $P V T 1$ and $C D 44$ in SNU-16 cells, respectively (14). PVTI has also been shown to be involved in three other fusions with PDHX, ATE1 and PPAPDC1A (14). In addition, SLC1A2, another fusion partner of $C D 44$, maps to chromosome 11 at p13-p12 (16). In the present study, the breakpoint of APIP at the fusion junction was in exon 5 of APIP-FGFR2, while exon 6 in PVT1-APIP was reported in a previous transcriptome study (14). These findings, together with our FISH data, suggested that $A P I P$ and $F G F R 2$ fuse with each other during the formation of PVT1-APIP and FGFR2-CD44 fusions, a process that is followed by their amplification. Chromothripsis, which is defined as a single catastrophic genetic event (25-27), is the most likely mechanism underlying the formation of these fusion genes with high-level genomic amplification, as suggested in similar reports detecting $P V T 1$ fusion genes in other tumors harboring dmins/hsrs (18-20). Further studies are required to elucidate the exact relationship between the gene fusion, hsrs and chromothripsis.

APIP encodes the APAF1-interacting protein, which has methylthioribulose 1-phosphate dehydratase activity and is involved in the methionine salvage pathway (28). APIP deficiency is associated with cell death and cancer $(29,30)$. By contrast, FGFR2, which is a member of the fibroblast growth factor receptor family, was detected in $\sim 16 \%$ of diffuse gastric cancers $(10,31)$. SNU-16 cells have two FGFR2 fusion genes, $A P I P-F G F R 2$ and $C D 44-F G F R 2$ (14), and exhibit overexpression of $F G F R 2$. Although it remains unclear how APIP-FGFR2 and CD44-FGFR2 are implicated in the tumorigenesis of gastric cancer, SNU-16 cells have been shown to be sensitive to FGFR inhibition; thus FGFR2 may be an important therapeutic target in gastric cancer (32). 
In conclusion, the present study described the APIP-FGFR2 fusion gene in gastric cancer with high-level genomic amplification, and demonstrated fusion signals in hsrs by FISH using probes for $10-\mathrm{kb}$ long-distance PCR products. The results of the present study indicated that genomic fusions of APIP and FGFR2 with a diversity of breakpoints are generated in hsrs resulting in several transcripts from rearranged alleles with either normal or alternative splicing.

\section{Acknowledgements}

The authors would like to thank Minako Goto and Kayoko Kurita for their technical assistance. This study was supported by a Grant-in-aid for Scientific Research (C) from the Ministry of Education, Culture, Sports, Science and Technology of Japan (grant no. 15K09486).

\section{References}

1. Hartgrink HH, Jansen EP, van Grieken NC and van de Velde CJ: Gastric cancer. Lancet 374: 477-490, 2009.

2. Jemal A, Bray F, Center MM, Ferlay J, Ward E and Forman D: Global cancer statistics. CA Cancer J Clin 61: 69-90, 2011.

3. Nakatsuru S, Yanagisawa A, Ichii S, Tahara E, Kato Y, Nakamura Y and Horii A: Somatic mutation of the APC gene in gastric cancer: Frequent mutations in very well differentiated adenocarcinoma and signet-ring cell carcinoma. Hum Mol Genet 1: 559-563, 1992.

4. Deng N, Goh LK, Wang H, Das K, Tao J, Tan IB, Zhang S, Lee M, Wu J, Lim KH, et al: A comprehensive survey of genomic alterations in gastric cancer reveals systematic patterns of molecular exclusivity and co-occurrence among distinct therapeutic targets. Gut 61: 673-684, 2012.

5. Wei J, Noto J, Zaika E, Romero-Gallo J, Correa P, El-Rifai W, Peek RM and Zaika A: Pathogenic bacterium Helicobacter pylori alters the expression profile of p53 protein isoforms and p53 response to cellular stresses. Proc Natl Acad Sci USA 109: E2543-E2550, 2012.

6. Li QL, Ito K, Sakakura C, Fukamachi H, Inoue Ki, Chi XZ, Lee KY, Nomura S, Lee CW, Han SB, et al: Causal relationship between the loss of RUNX3 expression and gastric cancer. Cell 109: 113-124, 2002.

7. Guilford P, Hopkins J, Harraway J, McLeod M, McLeod N, Harawira P, Taite H, Scoular R, Miller A and Reeve AE: E-cadherin germline mutations in familial gastric cancer. Nature 392: 402-405, 1998

8. Park WS, Oh RR, Park JY, Lee SH, Shin MS, Kim YS, Kim SY, Lee HK, Kim PJ, Oh ST, et al: Frequent somatic mutations of the beta-catenin gene in intestinal-type gastric cancer. Cancer Res 59: 4257-4260, 1999.

9. Choi JS, Seo J, Jung EJ, Kim EJ, Lee GK and Kim WH: c-MYC amplification in mucinous gastric carcinoma: A possible genetic alteration leading to deeply invasive tumors. Anticancer Res 32: 5031-5037, 2012

10. Hattori Y, Odagiri H, Nakatani H, Miyagawa K, Naito K, Sakamoto H, Katoh O, Yoshida T, Sugimura T and Terada M: $\mathrm{K}$-sam, an amplified gene in stomach cancer, is a member of the heparin-binding growth factor receptor genes. Proc Natl Acad Sci USA 87: 5983-5987, 1990.

11. Kuniyasu H, Yasui W, Kitadai Y, Yokozaki H, Ito H and Tahara E: Frequent amplification of the c-met gene in scirrhous type stomach cancer. Biochem Biophys Res Commun 189: 227-232, 1992

12. Kameda T, Yasui W, Yoshida K, Tsujino T, Nakayama H, Ito M Ito $\mathrm{H}$ and Tahara E: Expression of ERBB2 in human gastric carcinomas: Relationship between p185ERBB2 expression and the gene amplification. Cancer Res 50: 8002-8009, 1990.

13. Palanisamy N, Ateeq B, Kalyana-Sundaram S, Pflueger D, Ramnarayanan K, Shankar S,Han B, Cao Q, Cao X, Suleman K, et al: Rearrangements of the RAF kinase pathway in prostate cancer, gastric cancer and melanoma. Nat Med 16: 793-798, 2010.

14. Kim HP, Cho GA, Han SW, Shin JY, Jeong EG, Song SH, Lee WC, Lee KH, Bang D, Seo JS, et al: Novel fusion transcripts in human gastric cancer revealed by transcriptome analysis. Oncogene 33: 5434-5441, 2014.
15. Yun SM, Yoon K, Lee S, Kim E, Kong SH, Choe J, Kang JM, Han TS, Kim P, Choi Y, et al: PPP1R1B-STARD3 chimeric fusion transcript in human gastric cancer promotes tumorigenesis through activation of PI3K/AKT signaling. Oncogene 33: 5341-5347, 2014

16. Tao J, Deng NT, Ramnarayanan K, Huang B, Oh HK, Leong SH, Lim SS, Tan IB, Ooi CH, Wu J, et al: CD44-SLC1A2 gene fusions in gastric cancer. Sci Transl Med 3: 77ra30, 2011.

17. Yamashita Y, Nishida K, Okuda T, Nomura K, Matsumoto Y, Mitsufuji S, Horiike S, Hata H, Sakakura C, Hagiwara A, et al: Recurrent chromosomal rearrangements at bands $8 \mathrm{q} 24$ and 11q13 in gastric cancer as detected by multicolor spectral karyotyping. World J Gastroenterol 11: 5129-5135, 2005.

18. Campbell PJ, Stephens PJ, Pleasance ED, O'Meara S, Li H, Santarius T, Stebbings LA, Leroy C, Edkins S, Hardy C, et al: Identification of somatically acquired rearrangements in cancer using genome-wide massively parallel paired-end sequencing. Nat Genet 40: 722-729, 2008

19. Pleasance ED, Stephens PJ, O'Meara S, McBride DJ, Meynert A, Jones D, Lin ML, Beare D, Lau KW, Greenman C, et al: A small-cell lung cancer genome with complex signatures of tobacco exposure. Nature 463: 184-190, 2010.

20. Northcott PA, Shih DJ, Peacock J, Garzia L, Morrissy AS, Zichner T, Stütz AM, Korshunov A, Reimand J, Schumacher SE, et al: Subgroup-specific structural variation across 1,000 medulloblastoma genomes. Nature 488: 49-56, 2012.

21. Nannya Y, Sanada M, Nakazaki K, Hosoya N, Wang L, Hangaishi A, Kurokawa M, Chiba S, Bailey DK, Kennedy GC and Ogawa S: A robust algorithm for copy number detection using high-density oligonucleotide single nucleotide polymorphism genotyping arrays. Cancer Res 65: 6071-6079, 2005.

22. Chinen Y, Taki T, Nishida K, Shimizu D, Okuda T, Yoshida N, Kobayashi C, Koike K, Tsuchida M, Hayashi Y and Taniwaki M: Identification of the novel AML1 fusion partner gene, LAF4, a fusion partner of MLL, in childhood T-cell acute lymphoblastic leukemia with $\mathrm{t}(2 ; 21)(\mathrm{q} 11 ; \mathrm{q} 22)$ by bubble PCR method for cDNA. Oncogene 27: 2249-2256, 2008.

23. Nagoshi H, Taki T, Hanamura I, Nitta M, Otsuki T, Nishida K, Okuda K, Sakamoto N, Kobayashi S, Yamamoto-Sugitani M, et al: Frequent PVT1 rearrangement and novel chimeric genes PVT1-NBEA and PVT1-WWOX occur in multiple myeloma with $8 \mathrm{q} 24$ abnormality. Cancer Res 72: 4954-4962, 2012.

24. Holbrook JD, Parker JS, Gallagher KT, Halsey WS, Hughes AM, Weigman VJ, Lebowitz PF and Kumar R: Deep sequencing of gastric carcinoma reveals somatic mutations relevant to personalized medicine. J Transl Med 9: 119, 2011.

25. Korbel JO and Campbell PJ: Criteria for inference of chromothripsis in cancer genomes. Cell 152: 1226-1236, 2013.

26. Magrangeas F, Avet-Loiseau H, Munshi NC and Minvielle S: Chromothripsis identifies a rare and aggressive entity among newly diagnosed multiple myeloma patients. Blood 118: 675-678, 2011.

27. Stephens PJ, Greenman CD, Fu B, Yang F, Bignell GR, Mudie LJ, Pleasance ED, Lau KW, Beare D, Stebbings LA, et al: Massive genomic rearrangement acquired in a single catastrophic event during cancer development. Cell 144: 27-40, 2011.

28. Kang W, Hong SH, Lee HM, Kim NY, Lim YC, Le le TM, Lim B, Kim HC, Kim TY, Ashida H, et al: Structural and biochemical basis for the inhibition of cell death by APIP, a methionine salvage enzyme. Proc Natl Acad Sci USA 111: E54-E61, 2014.

29. Järvinen AK, Autio R, Haapa-Paananen S, Wolf M, Saarela M, Grénman R, Leivo I, Kallioniemi O, Mäkitie AA and Monni O: Identification of target genes in laryngeal squamous cell carcinoma by high-resolution copy number and gene expression microarray analyses. Oncogene 25: 6997-7008, 2006.

30. Moravcikova E, Krepela E, Prochazka J, Rousalova I, Cermak J and Benkova K: Down-regulated expression of apoptosis-associated genes APIP and UACA in non-small cell lung carcinoma. Int J Oncol 40: 2111-2121, 2012.

31. Nakatani H, Sakamoto H, Yoshida T, Yokota J, Tahara E, Sugimura $\mathrm{T}$ and Terada $\mathrm{M}$ : Isolation of an amplified DNA sequence in stomach cancer. Jpn J Cancer Res 81: 707-710, 1990.

32. Xie L, Su X, Zhang L, Yin X, Tang L, Zhang X, Xu Y, Gao Z, Liu K, Zhou M, et al: FGFR2 gene amplification in gastric cancer predicts sensitivity to the selective FGFR inhibitor AZD4547. Clin Cancer Res 19: 2572-2583, 2013. 